\title{
SIGNS OF RESISTANCE, VOICES OF DISSENT: \\ THE POLITICAL GRAFFITI \\ OF EL SALVADOR
}

\section{Dominic Smith}

The streets of San Salvador are full of extremes: Cherokee jeeps with bullet proof glass shuttle the elite to and from their pristine, armed guarded homes, while huddled beggars sit in the gutters, their hands outstretched. By day the streets are teeming with life. With an enormous volcano looming behind the cityscape, and national police guards toting their automatic rifles on every corner, the atmosphere can seem ominous. The markets bustle, vendors yell their prices, and the sometimes stifling heat can all make the city feel chaotic. By night, the city is often empty by nine o'clock and the air is quiet, save for the sound of sweepers and the occasional honk of a bus horn. The after-dark quietude is reminiscent of the civil war curfew, when families returned to their homes after work and risked their lives if they ventured out onto the streets at night.

The nights, however, have been a time of clandestine activity for many years in El Salvador. During the war and earlier, it was a time when political organizers could meet with their working class or campesino populations, when bands of men and women engaged in insurrection, secretly making their attacks against the state.

One type of group that participated in the night-time insurrection ventured out to communicate with the masses - to paint, write and paste messages wherever they could, on walls, awnings and even buses, any place that held the potential to be seen by the target audience. Though the themes of such messages differed, they all attempted to raise issues for the public eye, to manufacture a "newspaper"for the largely uneducated and marginally literate population of the Salvadoran working and peasant class. A key strategy to reach 

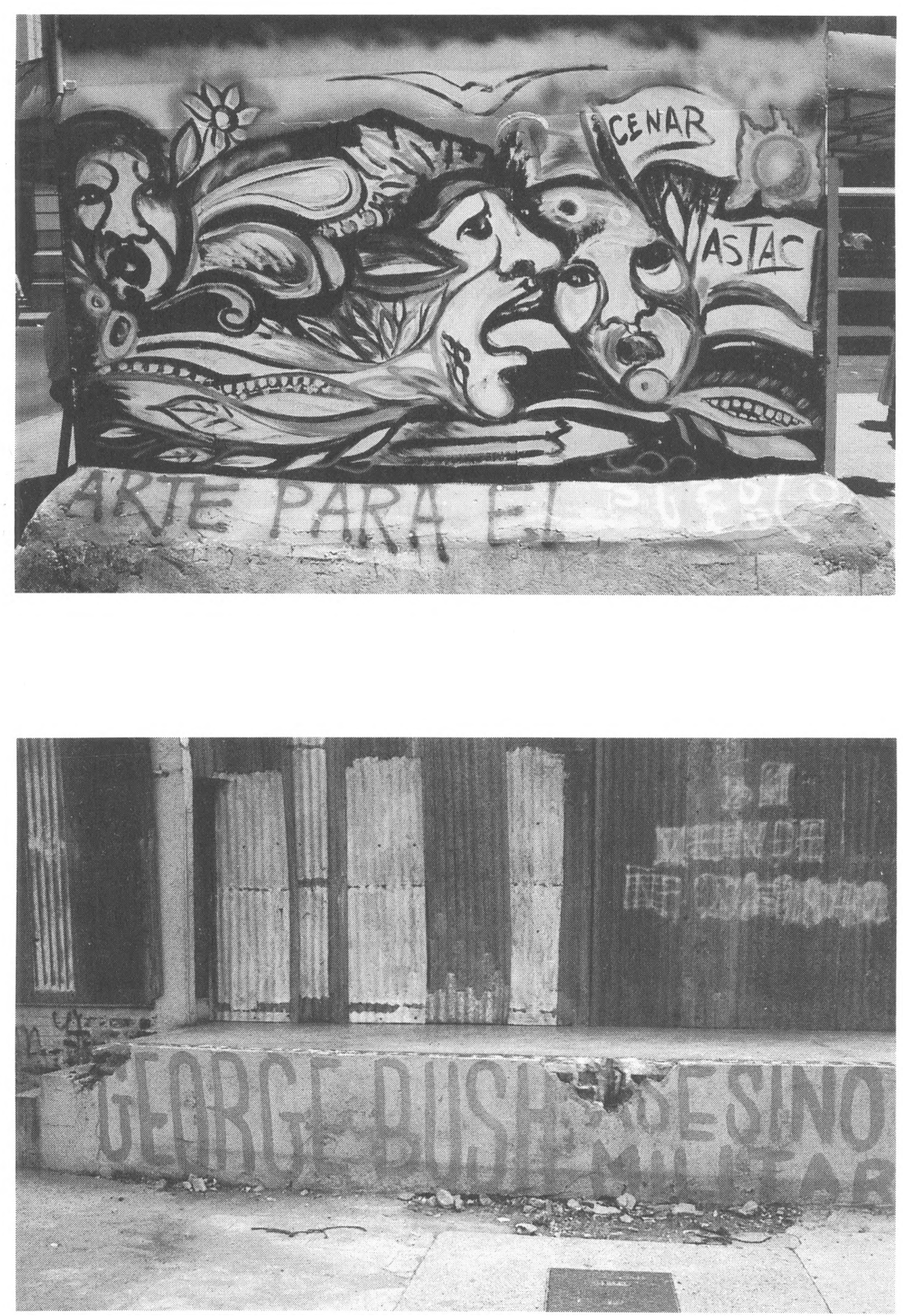
people in both city and rural areas was to paint graffiti, or las pintas as many Salvadorans in the popular movement call them.

A recent example of graffiti in El Salvador can be seen with an event that took place in May, 1993. Within a day of Salvadoran riotpolice killing several protesting war wounded outside the Presidential palace in San Salvador, the city filled with the familiar voices of graffiti messages. Across the awnings of shop fronts and in central plazas in the Capital appeared the words, THE POLICE ARE ASSASSINS. Thousands of messages, mostly written in red to symbolize the bloodshed, confirmed the event for countless Salvadorans without access to newspapers or electronic media, most of which are controlled by the right wing oligarchy.

That this kind of happening evoked such a public response is not surprising to Salvadorans. They have seen the form of graffiti evolve through twelve years of civil war into a legitimate voice of the masses, emerging as an index of dissent. During the large public protests of the late seventies and into the early phase of the civil war, graffiti in El Salvador was an essential communication strategy-it conveyed in simple terms the popular interpretation of an historical event, gave advice on how to act in resistance to the government, and acted as an affirmation of the continuing struggle. As clandestine groups emerged and reform agendas became covert, graffiti brigades were formed by the majority of factions agitating for social change. Typically, the graffiti brigade consisted of four or more members who wrote messages in both city and country areas. Security for these graffitimissions had to be tight since the penalty for such subversive activity would surely be torture, if not death. Though the brigade missions were often spontaneous, they usually carried a theme which was agreed upon by members of the group the brigade represented. Such a communication strategy was also used in the course of protest marches, where the commotion and crowds made it relatively easy to write messages and leave the site undetected.

There were times during the civil war when paint suppliers ran out of the popular black and blue colors used widely for Salvadoran graffiti messages. Paint was in short supply as both left and right wing forces used cities and village as canvasses for their agendas. In the remotest of villages one can still find remains of wartime graffiti. Written in bold, black lettering across a school house wall in rural Chalatenango is the message: ALL OF US RISE IN THE GREAT PROTEST OF THE NATION! Just a few feet away the wall reads, WITH PEN AND PAPER THE POPULAR TEACHERS ALSO FIGHT. Education in El Salvador has long been associated with the plight of the peasants and the struggle for social reform.

Gazing at the barrage of graffiti messages for the average Westerner in El Salvador can be a problem in interpretation. To the 

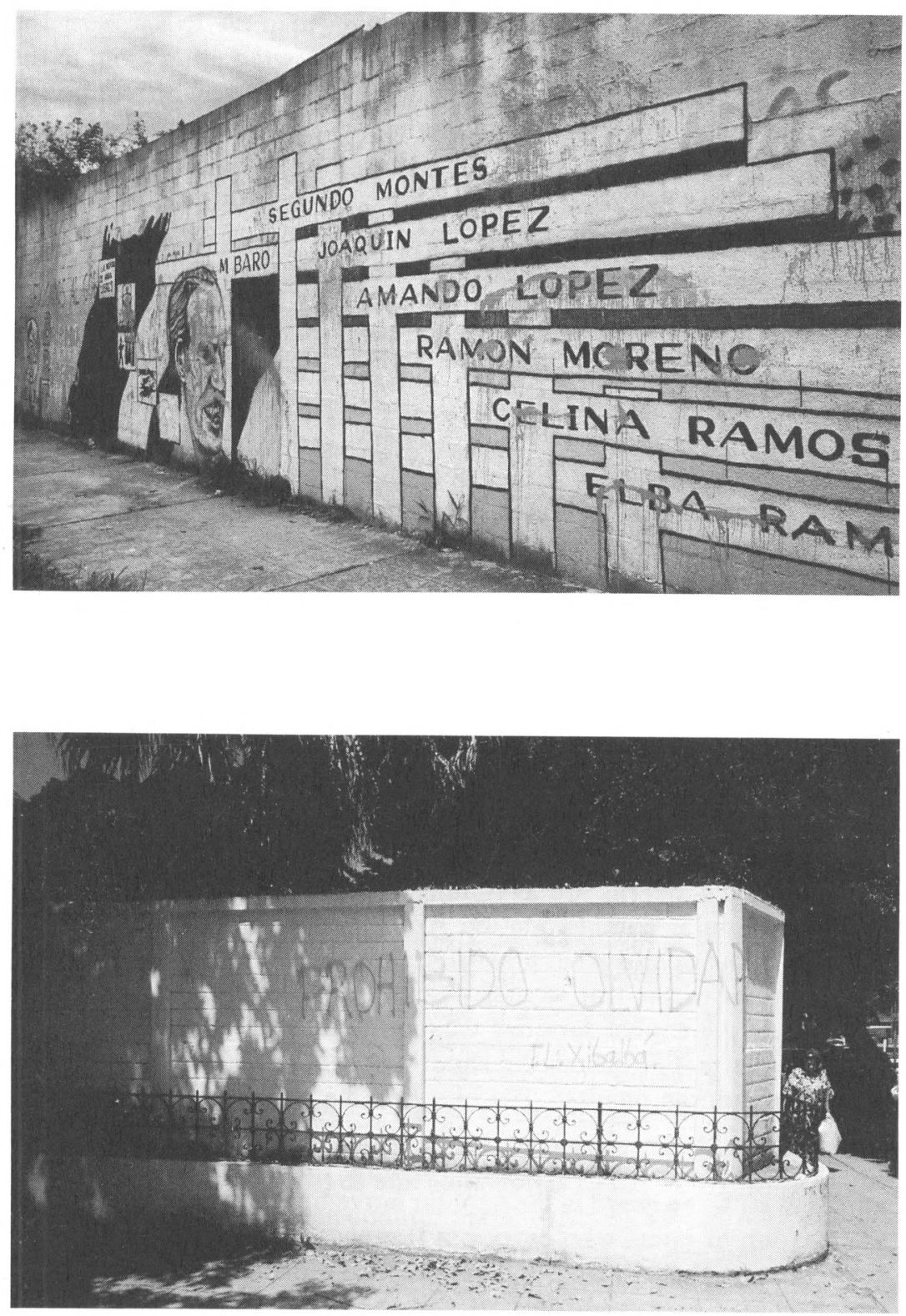
foreigner, the graffiti filled walls of the Hospital Rosario in the capital, for example, appear like a maze of scrawled letters, but to the initiated it actually represents more than fifteen years worth of political insurrection. The logos and comments of now extinct political parties appear in fading black and blue letters. Reading the text covered walls is like digging through the archaeology of the popular movement - the archaeology of resistance. Confusion for outsiders can arise when confronted with such messages that do not represent gangs, nor index crime and vandalism. In the U.S. so much organized, inner-city graffiti is about territory between rival gangs and achieving status and fame for the author. The graffiti message represents the writer's chance to address the world; it is a statement of anything from intent to fantasy. But in a nation like El Salvador, where the stakes of subversive communication have been in terms of individual lives, the form is changed, almost beyond recognition for the person of the First World. Though the message remains marginal from the eyes of the status quo, it is held by many as a national dialogue. It has, over the years, engaged nationally respected left-wing political leaders, poets, artists and writers. It has been seen as one of the few uncensored avenues for public opinion.

Today, El Salvador is not fighting a civil war though the political fire is heavy with the national elections scheduled for early 1994. In the peace process the political space has opened for all social groupsthe covert has become overt, the popular sphere has widened. One might expect that graffiti would decline now that more open means for stating one's concerns are available. Yet, it seems that while other forms of popular communication like newsletters and radio are advancing in the open space, graffiti remains important. When in May the shootings of the war wounded occurred, the public chose graffiti perhaps as their most familiar weapon against silence. Overnight, blood-red letters protested the shootings and voiced the age old rage of the Salvadoran people. The city became a text for the disenfranchised.

The group "Xibalbá" is an example of the sheer spectrum of voices that can be heard in the popular movement in El Salvador. They are a group of poets who carry out literacy campaigns and use their verse to raise consciousness. They are also prolific writers of graffiti, which comes in a multitude of forms-from memorials to urgent warnings and harsh criticisms of the right wing regime. The memorials list the names of fallen FMLN combatants or other subversives who have died for the popular struggle. They are a form of public recognition for courage and act as poignant reminders of the violence of war. For those who had friends die in the war, to find their loved one's names on a wall, however briefly, may offer some small consolation. 
Xibalbá claim their inspiration from a Mayan heritage. This is an interesting source for a poetic muse in a country where the indigenous population is less than $3 \%$, unlike neighboring Guatemala where it is as high as eighty. One reason for such a small Salvadoran population of direct Mayan descent is the 1932 uprising when tens of thousands of indigenous people were either killed or exiled. The issue, as always, was land reform.

But although there may not be much "pure" Mayan blood in El Salvador anymore, artists, like those in Xibalbá, use indigenous themes to convey a sense of history in their work. The group is also connected to many agents of dissent through history, merely through the act of graffiti. It was in ancient Rome where graffiti first came to the attention of the state. Countless public toilets were being covered by the observations of Roman citizens. In response, the government painted the toilets with murals of the pantheon of gods, declaring the act of graffiti an injunction on the supernatural and social order. One wonders if the Mayan empire with its state level structures ever encountered such a problem. Regardless, the world of the Maya, with its rich spheres of science, mathematics and artistry, is a source of encouragement for Xibalbá and other Salvadorans who feel they have had their own national identity robbed by European models of culture. This sense of history imbues many of their graffiti texts, such as a message in downtown San Salvador which simply reads, PROHIBITED TO FORGET.

With high hopes being placed on the upcoming election in El Salvador, graffiti as a national voice is undergoing a transformation. On the one hand, there is now freedom to engage in more artistic forms of communication such as murals which often attempt to instill confidence in people that the FMLN, after its guerrilla days of war, is a legitimate political party capable of delivering social justice. But despite the burgeoning of murals, the signs of graffiti continue to appear in the streets of El Salvador, decrying injustice and speaking from the heart of the masses. These days the occasional non-political graffiti message can also be seen. Many barrio peer groups are developing their own logos and adorning the streets with spray paint, much like their American counter parts. Although some may fear that the art of political graffiti may give way to the occasional narcissism of gang graffiti, it seems beneficial that greater freedom inevitably evokes greater diversity of expression. Perhaps a just society cannot have one without the other. 